\title{
IV. Report of C. Nowell, M. D. of Boulogne, correspondent of the committee of medicine, commissioned to repeat at Paris the experiments respecting the vaccine inoculation, to $\mathrm{C}$. Maselet, sub-prœfect of the district of Boulogne-sur-Mer
}

\section{J.M. Nowell M.D.}

To cite this article: J.M. Nowell M.D. (1801) IV. Report of C. Nowell, M. D. of Boulogne, correspondent of the committee of medicine, commissioned to repeat at Paris the experiments respecting the vaccine inoculation, to $C$. Maselet, sub-prøfect of the district of Boulogne-sur-Mer, Philosophical Magazine Series 1, 8:32, 309-313, DOI: 10.1080/14786440108562649

To link to this article: http://dx.doi.org/10.1080/14786440108562649

Published online: 25 Jan 2010.

Submit your article to this journal ¿

山 Article views: 2

View related articles 
inoculated a child from the cow-pock puftule furrounded by a clufter of fmall-pox; in thort, they appeared fo blended that I had my doubts whether the matter I obtained was that of the cow-pock or mixed with fmall-pox; indeed I was rather difpofed to think the latter was the cafe, as it did not appear fo limpid as it ufually does in the cow-pock. However, the refult is, that it produced the genuine cowpock without any appearance different from what $I$ have always feen; and with matter from this fource I have continued to inoculate ever fince, without any variation either in fymptoms or appearance. If this cafe fumilies you with any thing new on the fubject, I fhall be very glad. I have no time now to make any comment upon it, as the poft-office is juft going to thut. I am, Yours fincerely,

JOHN BRANSON.

P. S. Since I wrote laft to you, I have inoculated upwards of 500 for the vaccine difeafe, without any unpleafant fymptoms.

IV. Report of C. Noweul, M.D. of Boulogne, Correfpondent of the Committee of Mcdicine, commifjoned to repeat at Paris the Experiments refpecting the Vaccine Inoculation, to C. MAselet, Sub-Prafeet of the Diflria of Boulogine-jur-Mer*.

Y

$\mathrm{OU}$ are defirous of knowing the refults which $I$ have obtained refpecting the new inoculation known under the name of the vacinis. As it was you who firt patronifed it, when Dr. Woodville, Dr. Aubert, and myfelf, introduced it into Francet; and as it was you who triumphed over that coalition of prejudices, interefts, and paflions, which had armed againft it even the fupreme authority, you ought to be more interefted than any other perfor in the fuccefs and propagation of a difcovery which, without your afliftance, would have been rejected, together with the vefficl that brought it to your fellow-citizens.

* From Decade Pbiloropbique.

+ This is not true. The Vaccine Inoculation was introduced into France by the London Vaccine Inftitution. - See the Letter of the Ecole Mrdicale to Dr. Pearfon, in our Magazine for Auguif 1 \&oo, p. 279, \&c. 
Since the month of September, when I returned frore Boulogne, I have inoculated for the vaccine 160 fubjects of all ages, but the greater part children. All thefe different experiments, which were attended with the greateft fuccefs, have invariably difplayed that character of mildnefs which eftablithes, in an inconteftable manner, the fuperiority of the new over the old mode of inoculation; and the difference which we have had an opportunity of remarking in fome of the refults tends fill further,to confirm this fuperiority.

All the children and adults whom I inoculated during the whole courfe of the experiment continued their ufual fports and exercifes without feeling the leaft inconvenience. The adults followed their daily occupations, and in general experienced a very thort fenfation of uneafinels, and at moft a night febrile affection.

Six weeks after my firf experiments I made fucceffively feven counter-experiments. I carried to the houfe of C. Beaufoleil, whofe children were attacked with the natural fmall pox, the eruption of which was very abundant, three children of $\mathrm{C}$. Beugné, who had been inoculated with the vaccine. After leaving them a long time together, I inoculated my three fubjects, as ufual, with the variolous matter taken from the youngelt of the children, who was covered with the eruption; but none of them experienced the leaft effect from the operation.

The other four fubjects, whom I afterwards fubjected to a counter-experiment, were, a young domeftic of C. Wynne, another of $\mathrm{C}$. Bell, and two fifters of the latter. I carried them to the houfe of C. Trudin, broker, whofe child had the natural fmall-pox. They were all inoculated without the leaft effect.

C. Magnier, of Pont-de-Brique, having fent for his fon from Boulogne, where he was at fchool, I inoculated him with the vaccine in the country. He was then fent back to fchool, where the fmall-pox had broken out during his abfence. The young man continued as ufual to frequent the company of his fchool-fellows infected with the contagion, to play with them, to eat with them, and to fleep in the fame room with them, without experiencing any effect. 
I have had an opportunity in the courfe of my experiments to be convinced that the vaccine inoculation can have no effect on thofe who have had the fmall-pox. C. Beugné, already mentioned, believed that he had never had the fmallpox. I inoculated him three different times with the vaccine matter, but always without any effect. Being ftruck with this phænomenon, I afked him fome queftions, when he acknowledged, that at the age of four years he had flept with one of his fifters who had been attacked with the confluent finallpox highly malignant, that he had been very fick for feveral days, but that his mother did not think him infected with the fmall-pox becaufe he had no pultules, which are the ufual fymptom. This was an excellent opportunity for trying a new fort of counter-experiment: I inoculated C. Beugné with the fmall-pox, but they took no effect.

The fon of C. Genol, of Samer, aged nine years, had been inoculated for the vaccine with frefh matter and of a good quality. Four days after I went to examine the child, and was much furprifed to obferve that the vaccine had produced nothing, though the child had been inoculated in three different places. This experiment had feldom failed, except when the fubjeet had before had the fmall-pox. On examining the child, I found him with a languid look, a bad pulfe, and a great deal of fever. I fufpected, therefore, that he had been already infested with the fmall-pox at the time when I inoculated him for the vaccine. On inquiring, I found that the child had come from a houfe where the natural fmall-pox prevailed, in order to be inoculated. I fore$f_{a w}$ that he was going to have the natural eruption, and indeed.the difeafe appeared on bim two days after. It was of the mild kind, and the punctures made for the vaccine were ciry, and almoft effaced.

My experience proved to me alfo, that in the cafe where the fubject is already infected with the fmall-pox, the vaccine inoculation, which then remains without any apparent effect, adds nothing to the malignity of the fmall-pox. I am convinced that, whichever of the two infections is anterior in point of action aud progrefs, prevents the action and pro- 
grefs of the ather; and confequently, as thefe two principles cannot exift together, the one cannot add to the other.

Another very important obfervation, which appears to me to prove that the vaccine is really a fpecies of the fmall-pox, which differs from the human fmall-pox only by its origin and the peculiar character of mildnefs by which it is diftinguifhed, is as follows :-A child of C. Billier, falt-refiner, on the ninth day of inoculation for the vaccine, which is the critical day, cut four teeth, two of them eye-teeth. A fecond crifis of nature fo violent, ought to have been, and was accompanied with, a ftrong accefs of fever, which, added to the very moderate accefs arifing from the vaccine, brought out on the child's body an eruption of 262 large puftules flled with limpid matter. No common inoculation ever produced any of fo beautiful a kind; they ended without the leaft fever, and difappeared at the end of feven days without leaving any marks. This cbild fince inoculation has enjoyed perfect health ; and I have remarked that is invariably the effect of the vaccine. The cafe is far from being the fame with the common inoculation. Of the children whom I inoculated with-the vaccine, feveral were weak and ailing, often attacked with a violent cough, and two of them were wafted with a periodical fever. All thefe children, and in particular the two laft, have enjoyed fince the operation perfect health.

The vaccine inoculation ferves me as a criterion to diffipate. the uneafinefs of thofe who have need of being affured that they have had the fmall-pox, and that they have nothing to fear.

I have offered a premium for every poor perfon who can be proved to me to have had the fmall-pox after being inoculated, with care, for the vaccine. I flould not be afraid to rilk my whole fortune at prelent on this head. But I cannot too ftrongly recommend to practitioners to beftow more care on this operation, and to repeat it if the. leart doubt thould remain; otherwife there will be fome danger of feeing perfons attacked with the fmall-pox after being fuppofed fecured from that difeafe by the vaccine. It is to errors of this kind that the obftacles oppoled to the introduction 
duction of the common inoculation in the north of England were to be afcribed.

This ineftimable difcovery bas triumphed over all obftacles as well as over every prejudice in England. Sophifms have been refuted by facts ; and it is contrary to the rules of good logic to reply to facts by hypothefes. The celebrated Doctor David, of Rotterdam, wrote to me in the month of Oetober laft, that the experiments which he repeated with the matter fent from Boulogne had been attended with the moft complete fuccefs; and Dr. Jenner, the author of this noble difcovery, informed him at that period, that more than 50,000 perfons have been already inoculated with the vaccine in England; that a third of that number had been expofed to every teft polfible without the fmall-pox ever taking effect: and, in the laft place, for five years, during which time he has been conftantly employed in repeating the experiments, no one has ever yet refuted this theory, or weakened the conclufions he has drawn from it.

Boulogne-fur-Mer,

J. M. NOWELL, M.D. Dic. 3, 1800.

V. A fort View of the new Electrical Experiments performed by. Dr, Va MARUM.

7. [Concluded from Page 193.]

struck by lightning, feveral perfons, befides the common electric light, clearly obferved on it a regular train of light; and Beccaria gave to this phænomenon, which he endeavoured, without fuccefs, 10 imitate with his electric machine, the name of divergent electricity. Mr. Landriani requefted Dr. Van Marum to try an experiment of the fame kind with his large machine. Both thefe philofophers confidered this divergent electricity as an effect of the refiftance which metals oppofe to the influx of the electric matter when they have too fmall a diameter, and throw off at the fides the matter not received. To afcertain this fact, an iron wire, 's of an inch in diameter, was placed at fuch a diftance from 